\title{
American College of Obstetricians and Gynecologists
}

National Cancer Institute

\section{Source}

National Cancer Institute. American College of Obstetricians and Gynecologists. NCI

Thesaurus. Code C39310.

A national medical society for obstetricians and gynecologists. 